\title{
Investigation and Value of Qualitative and Quantitative Characteristics 10 of Genotypes of Figs
}

\author{
Tatjana Kokaj \\ ${ }^{1}$ Gene Bank, Institute of Plant Genetic Resource, Agriculture University of Tirana, Albania. \\ ${ }^{2}$ Rruga Siri Kodra, 131/1 Tirane, Albania.
}

\begin{abstract}
How to cite this paper: Tatjana Kokaj. (2021) Investigation and Value of Qualitative and Quantitative Characteristics 10 of Genotypes of Figs. International Journal of Food Science and Agriculture, 5(3), 448-454.

DOI: 10.26855/ijfsa.2021.09.015
\end{abstract}

Received: June 30, 2021

Accepted: July 25, 2021

Published: August 17, 2021

*Corresponding author: Tatjana Kokaj, Gene Bank, Institute of Plant Genetic Resource, Agriculture University of Tirana, Albania; Rruga Siri Kodra, 131/1 Tirane, Albania.

Email: tatjana.koka@hotmail.com

\begin{abstract}
The study was carried out using the germplasm of fig trees from the national collection at the Agriculture University of Tirana. The collection contains several varieties of fig collected from different areas for purposes of conservation and preventing further genepool depletion. 10 genotypes of fig were analysed for quantitative and qualitative characteristics. All genotypes express especially dominant traits such is: colour of fruit, internal colour of fruit, lenticels, taste of fruit, cavity of fruit, length of fruit, form of fruit, form of leaves, type of leaves, genetic traits. This study are analyses quantitave traits such as: weight fruit, weight of tree/fig, Weight is variable parameter and depend on the age of fig tree, growth of tree, variety of the fig tree as well as adaptions of land and climatic condition because varieties have different origin. At all varieties are adapted to soil and climatic condition due to varieties having different origins. All examined varieties, are well adapted to soil and climatic in climatic condition. For varieties which are with maturity of times weight of fig tree is different, in the first maturity of fruit fig weight is a big than second maturity of fig tree weight. There are the less beffer fig trees than uniffer figs. Dominant uniffer varieties mature in August-September. However, last year we analyses with method: Reference AOAC 934.06, Sugar 21.73 2018, 2019; acidity was analyses AOAC 942.15 g/l All parameters were analyses statistical.
\end{abstract}

\section{Keywords}

Fig, Qualitative, Quantitative Characteristic, Diversity, Productivity

\section{Introduction}

Fig tree in Albania country is fruit important and older, very reach and a lot of sorts. Has more destination: 1. For fresh consume, 2. For dry consume, 3. For industry (jam, rakee). It is popular fruit, in every garden and orchard of private family you can found two or more fig tree one variety or two or three variety. Before years ago when economy was collective has been more block with figs, but more when economy pass in private economy this block separate in private family for administration. Creating a collection of fruit and fig species in particular as one of the most varied species in our country was a necessity of the time. There is now a collection that has a rich germoplasm of fig species from all over the country.

\section{Materials and methods}

The study was conducted during 2016-2019 and has analyses of morphological, phenological traits in 16 genotypes, but in this study, we will expose only 10 genotypes varieties which are in ex situ collection. The analyses were carried out of 10-20 leaves, 10-20 fruit for 10 genotypes. For 10 genotypes were analyses some characteristics such are: For leaves, dimension (length $\mathrm{x}$ width), lobes number, forms of leaf, type of leaf, sinus, etc, and for fruits, dimension of fruit 
(length $\mathrm{x}$ width), forms of fruit, color of fruit, age of tree, destination of fruit, crops number, weight of fruit, weight of tree, \% sugar, \% acidity, humidity, etc. At all characterizes of genotypes were characterization according descriptor of ECPGR, IPGRI, and composed passport for each accessions.

\section{Results and discussion}

From the study of 10 genotypes figs in the germplasm field is arrived in conclusion results that represent a visible genetic variability which consists of the leaf shape in the form of the crown in the form of fruit, represent a large variability of the traits. In foliar analysis, the foliage variability apparent in the form of leaf which moves from type A to type $\mathrm{H}$, number of lobes from 3 lobes to 5 lobes, type of leaves from spatulate to lyrate, form of leaves base from trunk to decurrant [1]. In addition to the genetic features, the phenotypic features of the plant as well as the dimensions of the leaf, dimensions of the tail, sinuses are analyzed. All are photographed and statistically analyzed.

Table 1. Indexs of accessions leaves ex situ collection Valias/UBTirane

\begin{tabular}{ccccccccccc}
\hline No. & Code/national & Code/bgj & Ll/cm & llxlw & llxlw & $\begin{array}{c}\text { Type of } \\
\text { leaves }\end{array}$ & $\begin{array}{c}\text { Shape of } \\
\text { leaf base }\end{array}$ & $\begin{array}{c}\text { Leaf } \\
\text { stalk } \\
\text { length }\end{array}$ & $\begin{array}{c}\text { Petiol of } \\
\text { length/cm }\end{array}$ & $\begin{array}{c}\text { Density of } \\
\text { hear }\end{array}$ \\
\hline 13 & ALB026 & 4246 & 19.0 & 18.5 & 351.5 & E & cordate & 6.6 & 6.5 & none \\
2 & ALBO26 & 4244 & 19.5 & 19.2 & 374.4 & G & decurrently & 7.0 & 7.0 & none \\
3 & ALB026 & 4243 & 15.0 & 15.4 & 231.0 & B & cordate & 10.5 & 5.0 & intermediate \\
4 & ALB026 & 4235 & 15.0 & 15.5 & 232.5 & G & decurrente & 7.8 & 5.0 & sparse \\
5 & ALB026 & 4238 & 17.0 & 14.0 & 238.0 & B & cordate & 7.5 & 6.0 & intermediate \\
6 & ALB026 & 4240 & 20.0 & 19.0 & 380.0 & D & calcarate & 6.6 & 6.0 & intermediate \\
7 & ALB026 & 4234 & 19.0 & 16.5 & 313.5 & G & decurrently & 6.7 & 9.0 & intermediate \\
8 & ALB026 & -------- & 20.0 & 19.0 & 380.0 & D & calcarate & 6.6 & 6.0 & intermediate \\
9 & ALB026 & 4237 & 19.0 & 16.5 & 313.5 & G & decurrently & 6.7 & 9.0 & intermediate \\
10 & ALB026 & 4239 & 21.0 & 19.0 & 399.0 & B & cordite & 6.5 & 8.0 & intermediate \\
\hline
\end{tabular}

\section{Clustering History}

\begin{tabular}{cccc}
\hline Number of Clusters & Distance & Leader & Joiner \\
13 & 0.594754460 & 5 & 12 \\
13 & 0.594754460 & 5 & 12 \\
12 & 0.798004456 & 6 & 13 \\
11 & 1.111620413 & 6 & 14 \\
10 & 1.300695333 & 4 & 11 \\
9 & 1.393160712 & 1 & 2 \\
8 & 1.489857821 & 5 & 6 \\
7 & 1.587540605 & 4 & 15 \\
6 & 1.668723370 & 3 & 8 \\
5 & 2.065863034 & 1 & 5 \\
2 & 2.307710288 & 1 & 3
\end{tabular}




\section{Multivariate}

Principal components/ factor analyses and correlations

\begin{tabular}{|c|c|c|c|c|c|}
\hline Number & Eigen value & & Percent & \multicolumn{2}{|c|}{ cum percent } \\
\hline 1 & 2.2806 & & 45.611 & \multicolumn{2}{|c|}{45.611} \\
\hline 2 & 1.2885 & & 25.771 & \multicolumn{2}{|c|}{71.382} \\
\hline 3 & 0.7948 & & 15.896 & \multicolumn{2}{|c|}{87.278} \\
\hline 4 & 0.4924 & & 9. 849 & \multicolumn{2}{|c|}{97.127} \\
\hline 5 & 0.1437 & & 2.873 & \multicolumn{2}{|c|}{ 100.000Eigenvectors } \\
\hline Length leave & 0.59439 & -0.11787 & 0.36163 & -0.03014 & 0.70790 \\
\hline Width leave & 0.58997 & 0.08406 & 0.32756 & -0.31494 & -0.66211 \\
\hline Length leave & 0.49442 & 0.08080 & -0.48344 & 0.70694 & -0.12462 \\
\hline Sinuses length sec & 0.14026 & 0.73375 & -0.44334 & -0.44780 & 0.21182 \\
\hline No of lobe & -0.18577 & 0.65888 & 0.57590 & 0.44678 & -0.00948 \\
\hline
\end{tabular}

Statistical analysis of fig leaves statistically confirms a great variability, a noticeable diversity, has a variable distribution, within leaf traits there are deviations and variations but and within varieties there is variability visible in leaf form, at its base, in the number of lobes.

In terms of quantitative indicators of leaf distance, leaf area variability is not large and is influenced by environmental factors and is a phenotypic variation.

\section{Distance leaves}

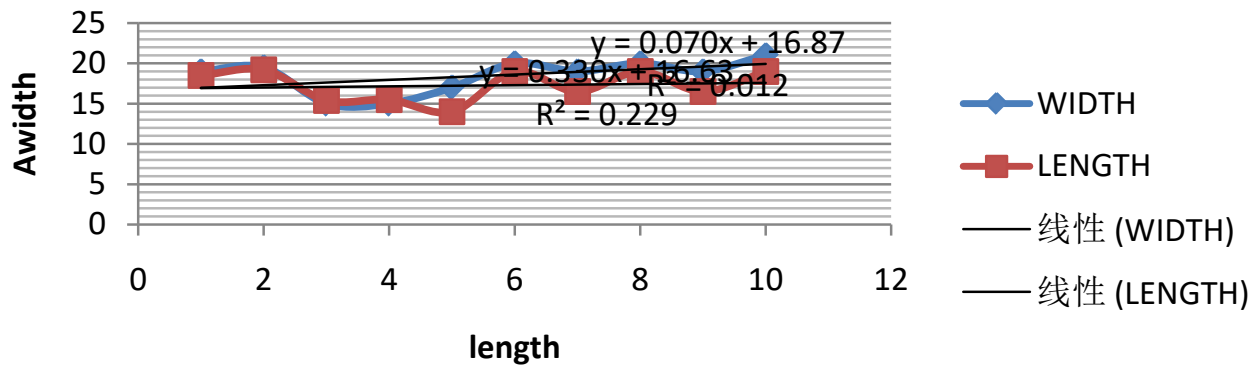

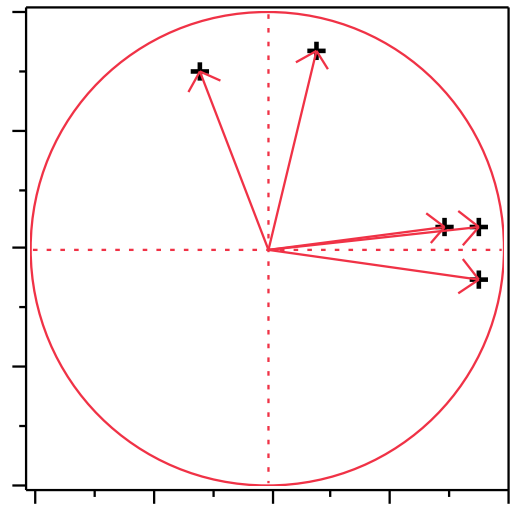

Loading Plot

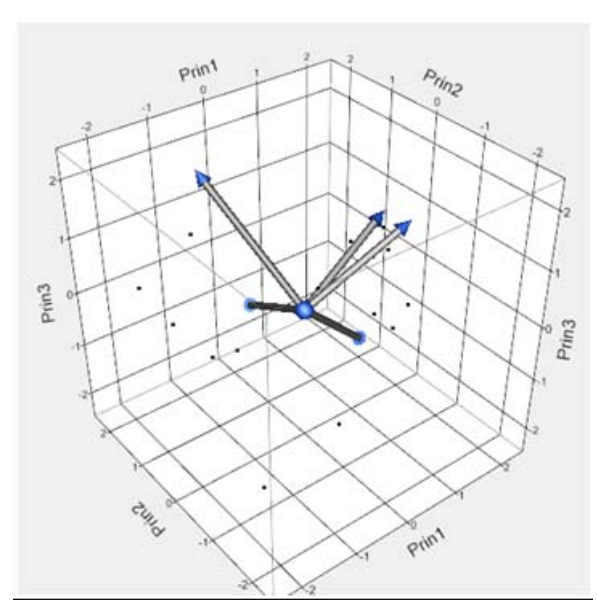

Scatter plot 3D

Figure 1. Distance leaf.

Sinus is one main index of genetic diversity which exposed distance between sorts. 


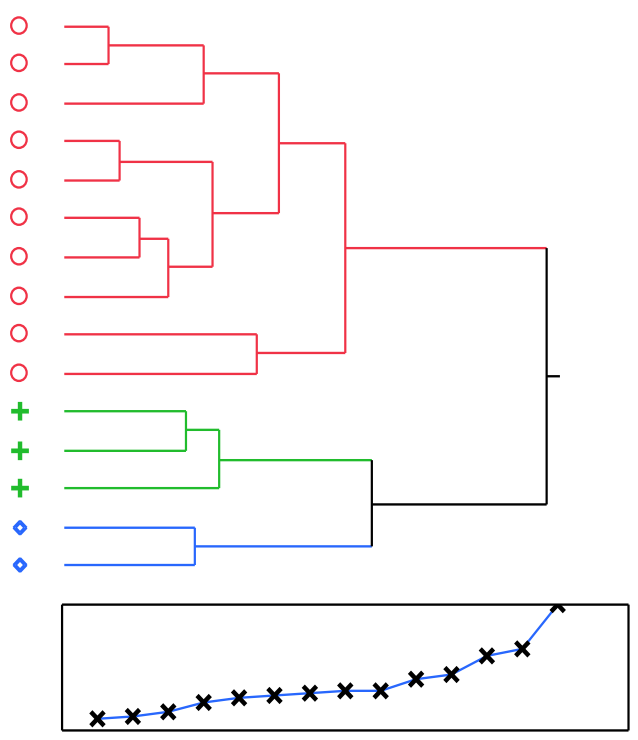

Figure 2. Dendogram 1 of leaves analyses.

In this dendograms, they are determinate three groups which are grouped according same or similar traits. Eight genotypes are grouped in one group, three genotypes are grouped in the second group for similar traits and two genotypes are grouped in the third group for similar traits. The traits of one group genotypes don't found in different groups, this is index which shows us for determination traits, dominant. The color fruit of figs tree are to link with polyphenols, flavonoids, anthocyanins and antioxidant capacity. Extracts of dark varieties showed higher content of photochemical and antioxidant compared to lighter colored varieties. In this collection found different color fruit from black to red, to violet to dark green to green etc. This index show for chemical elements which determination fruit color and pulp color and those are ant cyan and polyphenol groups.

Table 2. Index's of fruit figs genotypes for 2018, 2019 years

\begin{tabular}{ccccccccc}
\hline No & Code & $\begin{array}{c}\text { Fruit distance } \\
\text { (length width) } \mathrm{cm}\end{array}$ & $\begin{array}{c}\text { Weight fruit GR } \\
/ 2018\end{array}$ & $\begin{array}{c}\text { Weight fruit go } \\
/ 2019\end{array}$ & $\begin{array}{c}\text { \% Sugar } \\
/ 2018\end{array}$ & $\begin{array}{c}\text { \% Sugar/ } \\
2019\end{array}$ & $\begin{array}{c}\text { Maturity } \\
2018\end{array}$ & $\begin{array}{c}\text { Maturity } \\
2019\end{array}$ \\
\hline 1 & ALB026 & $3.5 \times 2.5$ & 25 & 20 & 11 & 16 & 5 August & 25 August \\
2 & Al026 & $5.5 \times 6.0$ & 43 & 40 & 11 & 26 & 5 August & 26 August \\
3 & ALBO26 & $4.5 \times 5.0$ & 55 & 50 & 17 & 26 & 5 August & 25 August \\
4 & ALB026 & $4.0 \times 4.5 .0$ & 42 & 40 & 13 & 23 & 5 August & 15 August \\
5 & ALB026 & $6.0 \times 7.2$ & 70 & 70 & 11 & 22 & 5 August & 25 August \\
6 & ALB026 & $6.0 \times 5.0$ & 40 & 35 & 17 & 15 & 5 August & 25 August \\
7 & ALB026 & $5.0 \times 5.0$ & 43 & 40 & 20 & 23 & 5 August & 29 August \\
8 & ALB026 & $4.5 \times 5.0$ & 35 & 30 & 21 & 29 & 5 August & 25 August \\
9 & ALB026 & $6.0 \times 6.0$ & 75 & 70 & 19 & 21 & 5 August 25 August \\
10 & ALB026 & $5.5 \times 5$ & 46 & 17 & 19 & 5 August & 25 August \\
\hline
\end{tabular}

In Table 2, it analyzed three main traits of fruit, distance, fruit weight and \% sugars were analyzed, fruit distance is different in the 10 fig genotypes, the other trait is fruit weight which differs from one varieties to another. Weight is a quantitative trait and depends on agronomic factors [2], the time of fruit ripening is different for each variety but in 2018 fruit have been ripe 5-10 days ago, as a result of the temperatures that characterized 2018 as explained below. In 2019, fruit ripening was realized in time. This collection has some fig varieties with a variety of fruit color from dark green to light green, to violet to black. The diversity of color is very noticeable [2]. Another traits is the internal pulp which is different in different varieties, diversity between varieties is the very visible, this traits are different from one to others varieties. We can find the figs varieties with same color but different in traits in pulp color, in taste, in seed number, in cavity, in destination of fruit, in time of ripening, in pollination request, etc. 


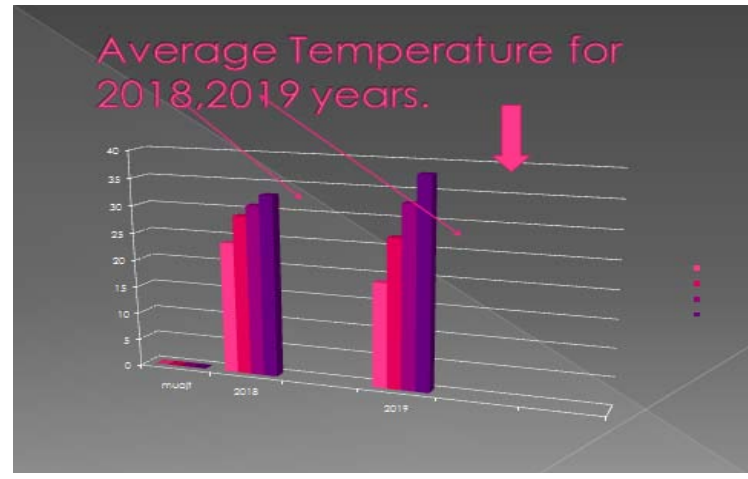

Figures 3. Average temperature for 2018, 2019 years.

In Figure 3, temperatures during the years have been characterized by a rise in temperature above forecast normal. In May, the difference was $2.2^{\circ} \mathrm{C}$. In June, there was a difference of $2^{\circ} \mathrm{C}$ and an amount of rainfall. Within one day up to 25 millimeters of rain per day. In August, begins stabilization with a deviation of $1.9^{\circ} \mathrm{C}$. This temperature has had an impact on the growth, ripening and formation of fig fruit. For 2018, it was observed a deviation from the normal of 5-10 days ago and not only in one variety but in all varieties in the collection. During the year there was an increase in fruit size but also a wet until fermentation in the branches caused the sugar content to be lower. For 2019, we have a very different situation, in May the temperatures are the same as in April, lower than previous years around $-1.1^{\circ} \mathrm{C}$, accompanied by heavy rains and intensities throughout May. Temp had a decrease $-1.9^{\circ} \mathrm{C}$. In June, normality with the report began. In July the temperatures reached $30-33^{\circ} \mathrm{C}$ [18]. In August, the temp marked a rise after 8 days to $38-40^{\circ} \mathrm{C}$ a rise of $1-4^{\circ} \mathrm{C}$. Certainly, the climate elements as the main elements of fig vegetation had its effects on the delay in ripening compared to the previous year.

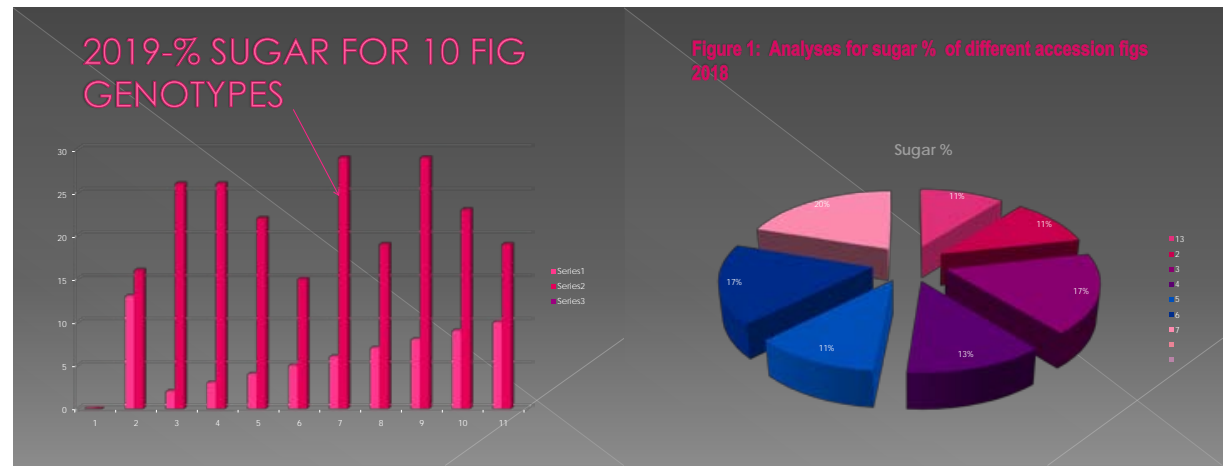

Figures 4. Percent of Sugar, for 2018, 2019 years.

In Figure 4, we can observed a different varieties figs with different sugar percent which begin $10-11 \%-22--22 \%$. The percent of sugar depend from ripening time, from intensity solar, from temperature in the time of maturity. From year to year, the percent of sugar is different, moving from year to year $2-4 \%$, in the last year the ripening phase has moved 5-10 days. In this graphic, we analyzed acidity content which is different in different of genotypes fig. We can observed acidity content is low, because is high the percent of sugar. When the percent of sugar is high the percent of acidity is low.

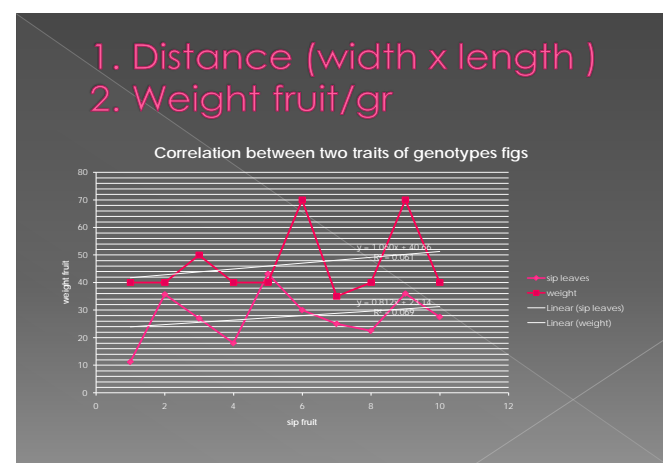

Figure 5. Correlation of two traits.

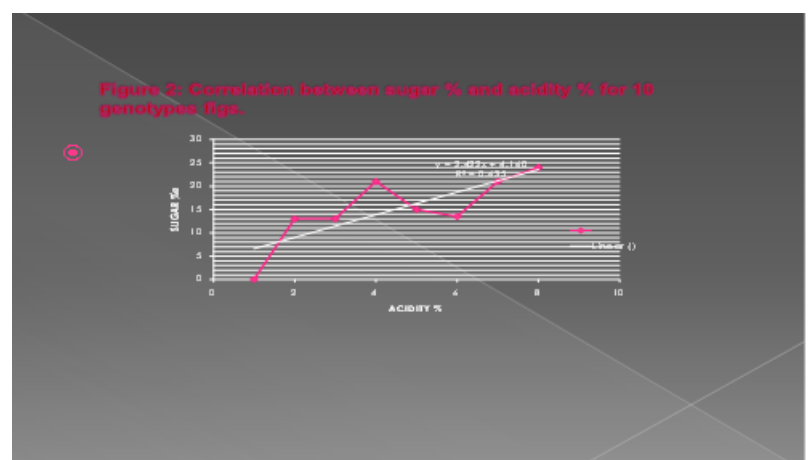

Figure 6. Correlation between sugar and acidity. 
Weight is trait important of fruit for market with fresh destination. This traits is link with dimension fruit (width $\mathrm{x}$ length), surface fruit according Figure 5. In this correlation, Figure 6 showed link between traits, $r=0.069$ is positive.

This is a simple correlation, coefficient that measures the strength of the linear relationship $\mathrm{y}$ and $\mathrm{x}$ and $\mathrm{r}=0.6$. 635. This the correlation is a positive correlation. This correlation coefficient (r) measures the linear relationship between the values of $\mathrm{x}$ and the values of $\mathrm{y}$. The value of $\mathrm{y}$ is a dependent value and the value of $\mathrm{x}$ is independent value. In this study, some traits in the 10 fig genotypes were characterized. The main features are qualitative and quantitative. Based on the molecular study conducted in 2016 in collaboration with P. Resta and T. Koka, it has been possible to identify the diversity of the varieties and their similarity [4]. Which varieties have common traits and which have their own characteristics that are not related to other varieties (see Figure 7 and Figure 8). The study found that links between varieties, and others are peculiar in their kind. All 10 genotypes are presented in the collection in Valias/UBTirane.

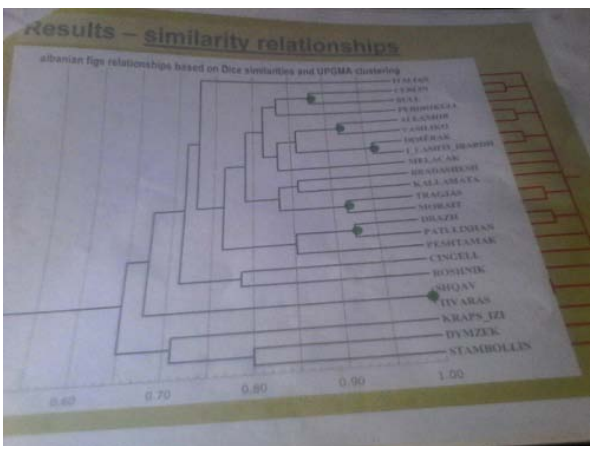

Figure 7. Dendogram of AND, molecular identification fig varieties.

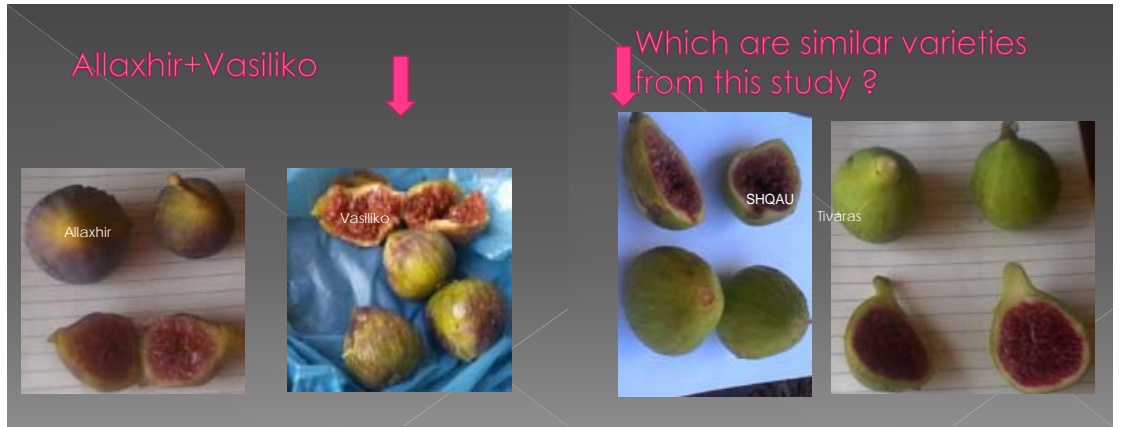

Figure 8. Similar varieties.

\section{Documentation}

The other phase of this study is documentation of figs genotype according ECPGR documentation; this documentation is different in the characterization and classification. Until now, we are in registration phase and are not on informatization system in the ECPGR, We hope in the future (see Figure 9).

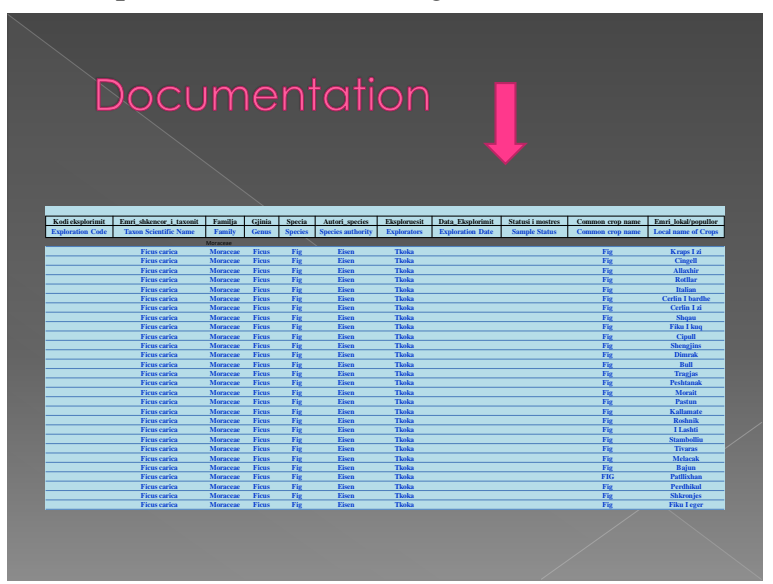

Figure 9. Documentation according ECPGR. 


\section{Conclusion}

From the study, it seems very clear that all 10 genotypes of figs have very valuable qualitative and quantitative features and with a very obvious diversity. In all its features, this diversity is visible both visually and chemically, molecularly and statistically. And in quantitative terms, it has a high productivity and an adaptability to soil conditions.

\section{References}

[1] Aksoy, U., Seferoglu, G., Misirli, A., Kara, S., Sahin, N., Bulbul, S., and Duzbastilar, M. (1992). Selection of the table fig genotypes suitable for Egean Region. I. Paper presented at: Proceeding of the First National Hortic Congress (in Turkish).

[2] Flaishman, A., Rodov, V., and Stover, E. (2008). The fig botany horticulture and breeding, Hortic. Rev (Am. Soc. Hortic. Sci), 34, 113-197.

[3] Flaishman, M. A. and Al Hadi, F. A. (2002). Fig growth in Israel. Halon Hanotea, 56-57.

[4] Ferrara, E. and Papa, G. (2003). Evaluation of fig cultivars for Breba crop. Acta Hortic, 605, 91-93.

[5] Gholami, M., Rahemi, M., Kholdebarin, B., and Rastegar, S. (2012). Biochimical responses in leaves of four fig cultivars subjected to water stress and recovery. Sci Hortic (Amsterdam), 143, 7-14.

[6] Hartman, H. T., Kester, D. E., Davies, F. T. Junior, and Geneve, R. L. (2002). Plant Propagation: Principles and Practices, 7 (New Jersey: Prentice Hall), p. 880.

[7] Javanmard, M., Abdolahi Pour Haghighi, J., and Zare, H. (2012). Mulching impact on plant growth and production of rainfed fig orchards under drought conditions. J. Food Agric. Environ., 10(1), 428-433.

[8] Kai, M., Fen, I. Z., Fen, T. Y., and Weibing, J. (1997). The green cutting propagation techniques for fig trees. China Fruits, 3, 32-38.

[9] Lianju, W., Weibin, J., Kai, M., Zhifeng, L., and Yelin, W. (2003). The production and research of fig (Ficus carica L) in China. Acta Hortic, 24, 44-50.

[10] M. Aradhya, J. E. Preece, and D. Velasco. (2017). Multivariate analysis of molecular and morphological diversity in Fig (Ficus carica L.). ActaHort, 1173, 23-28.

[11] Mowry, H. (1925). Growing fig in Florida. Prc, Fla. State Hort, Soc, 38, 92-97.

[12] Melgas, P. (2000). Tradato de Fruticultura para Zonas Aridas y Semiaridas El Medio Ecologico, la Higuera el Alcaparro y el Nopal (Madrit, Spain: S.AMundi-Prensa), p. 375.

[13] O. Caliscan, S. Bayazit, M. Ilgin, N. Karatas, and H. Kocatas. (2017). Preliminary results on morpho-pomologichal traits and pollinizer characterization of some caprifig genotypes grown in Eastern Mediterranean region of Turkey. Acta Horticulturae, $1173,45-48$.

[14] R. Mafrica, A. Marchese, M. Bruno, F. Costa, S. Fretto, F. P. Marra, S. Pangallo, A. Quartararo, and T. Caruso. Morphological and molecular variability within the fig cultivar "Dottato" in the Italian protected designation origin area "Fichi di Cosenza".

[15] Rossello I Botei, J. (2007). Characteritzacio de cultivars de Figuera a Mallorca (ED Govern de les Illes Balears, Conselleria dAgricultura I Pesca), p. 175.

[16] Stover, E., Aradhya, M., Ferguson, L., and Cris. The fig overview of an ancient fruit. Hortscience 42, 1083.

[17] Trad, M. C., Galiche, B., Renard, C. M. G. C., and Ferguson, L. (2013). Plant natural resources and fruit characteristics of fig (Ficus carica L) change from coastal to continental areas of Tunisia. E3 Journal of Agricultural Research and Development, 3, 22-25.

[18] Zorba, P. (2019). Buletini klimatik, 2019. 